\title{
Nutrient availability affects carbon turnover and microbial physiology differently in topsoil and subsoil under a temperate grassland
}

\author{
Zhi Liang*, Jørgen Eivind Olesen, Johannes Lund Jensen, Lars Elsgaard \\ Department of Agroecology, Aarhus University, Blichers Allé 20, 8830 Tjele, Denmark
}

\section{A R T I C L E I N F O}

Handling Editor: A.B. McBratney

Keywords:

Nutrient stoichiometry

Carbon turnover

Microbial activity

Nitrogen limitation

Subsoil

\begin{abstract}
A B S T R A C T
Increasing subsoil organic carbon (C) inputs could potentially mitigate climate change by sequestering atmospheric $\mathrm{CO}_{2}$. Yet, microbial turnover and stabilization of labile $\mathrm{C}$ in subsoils are regulated by complex mechanisms including the availability of nitrogen $(\mathrm{N})$, phosphorous $(\mathrm{P})$, and sulfur $(\mathrm{S})$. The present study mimicked labile organic $\mathrm{C}$ input using a versatile substrate (glucose) to address the interaction between C-induced mineralization, N-P-S availability, and microbial physiology in topsoil $(20 \mathrm{~cm})$ and subsoil $(60,100$, and $300 \mathrm{~cm})$ from a temperate agricultural sandy loam soil. A factorial incubation study (42 days) showed that net losses of added $C$ in topsoil were constant, whereas $C$ losses in subsoils varied according to nutrient treatments. Glucose added to subsoil in combination with $\mathrm{N}$ was fully depleted, whereas glucose added alone or in combination with $\mathrm{P}$ and $\mathrm{S}$ was only partly depleted, and remarkably $59-92 \%$ of the added glucose was recovered after the incubation. This showed that $\mathrm{N}$ limitation largely controlled $\mathrm{C}$ turnover in the subsoil, which was also reflected by microbial processes where addition of glucose and $\mathrm{N}$ increased $\beta$-glucosidase activity, which was positively correlated to the maximum $\mathrm{CO}_{2}$ production rate during incubation. The importance of $\mathrm{N}$ limitation was substantiated by subsoil profiles of $\mathrm{C}$ source utilization, where microbial metabolic diversity was mainly related to the absence or presence of added N. Overall, the results documented that labile $\mathrm{C}$ turnover and microbial functions in a temperate agricultural subsoil was controlled to a large extent by $\mathrm{N}$ availability. Effects of glucoseinduced microbial activity on subsoil physical properties remained ambiguous due to apparent chemical effects of $\mathrm{N}$ (nitrate) on clay dispersibility.
\end{abstract}

\section{Introduction}

Globally, subsoils ( $>0.2 \mathrm{~m}$ ) contain more than two thirds of the soil organic carbon (SOC) within the upper $3 \mathrm{~m}$ soil profile (Jobbagy and Jackson, 2000). Thus, despite of low SOC concentrations in mineral subsoils, their extensive volume holds the potential for substantial carbon (C) sequestration (Jobbagy and Jackson, 2000; Rumpel, 2014). This is supported by generally slow rates of $\mathrm{C}$ turnover in subsoils as evidenced by high mean ${ }^{14} \mathrm{C}$-SOC ages (Rumpel and Kögel-Knabner, 2011). The delineation of subsoils is not strictly defined, but in agroecosystems it is usually considered as the soil below the plough layer or A horizon.

Management of agroecosystems to enhance subsoil organic C storage could potentially be a strategy to mitigate climate change by reducing the increase in atmospheric $\mathrm{CO}_{2}$ concentration (Lorenz and Lal, 2005; Kell, 2011; Lynch and Wojciechowski, 2015). Principally, organic $\mathrm{C}$ sequestration in subsoils is controlled by the balance between organic matter inputs and losses. Inputs occur predominantly in the form of plant litter, rhizodeposition (including root exudates), and dissolved organic C, whereas losses mainly result from microbial respiration, which is linked to microbial population dynamics and activity (Fernandes et al., 1997; Hedges et al., 2000; Michalzik et al., 2003; Wilhelm et al., 2004). Hence, organic C inputs, e.g., by deep rooted crops, are required for increasing the subsoil $\mathrm{C}$ content, but the eventual long-term $\mathrm{C}$ sequestration depends on the interaction between $\mathrm{C}$ input and microbial activity, also involving physico-chemical mechanisms of C stabilization (Salomé et al., 2010; von Lutzow et al., 2006). It is generally acknowledged that three major mechanisms control the persistence of organic C in soils, i.e., (i) selective preservation through chemical recalcitrance of organic substrates, (ii) physico-chemical stabilization through interaction between organic $\mathrm{C}$ and soil minerals, and (iii) spatial separation of organic $\mathrm{C}$ from decomposition by microbes and extracellular enzymes (Krull et al., 2003; Lorenz and Lal, 2005; Schmidt et al., 2011). In nutrient poor subsoils, microbial mineralization of deposited organic $\mathrm{C}$ could also be limited by stoichiometric constraints in the availability of nitrogen $(\mathrm{N})$, phosphorous $(\mathrm{P})$ and/or

\footnotetext{
* Corresponding author.

E-mail address: zhi.liang@agro.au.dk (Z. Liang).
} 


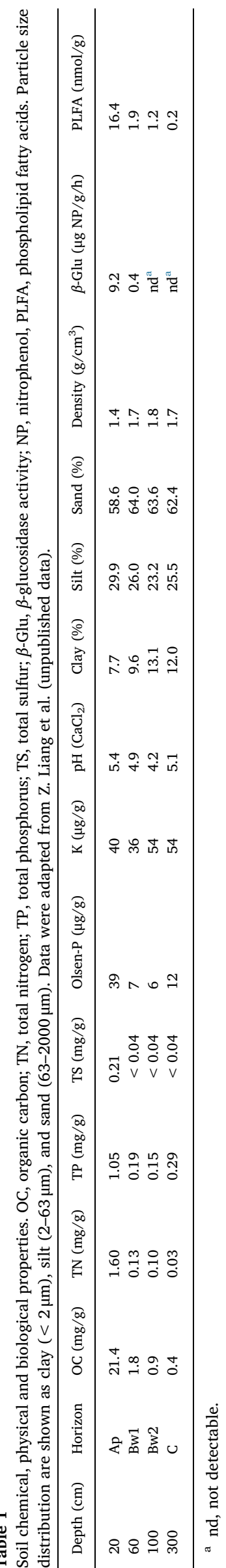

sulfur (S) as related to the requirements in microbial biomass, where C:N:P:S typically occur at a ratio of around 100:15:2:1 (Xu et al., 2013, 2015). As shown in studies of Australian soils, sequestration of stable organic C in subsoils may eventually depend on products of microbial anabolism, which are enhanced by balanced stoichiometry of C:N:P:S according to microbial biomass requirements (Orgill et al., 2017). Yet, a recent study of acidic tropical forest and plantation soil concluded that the role of subsoil as a long-term sink of SOC could be questioned under conditions of increased $\mathrm{N}$ and $\mathrm{P}$ availability due to alleviation of microbial nutrient limitation (Meyer et al., 2018). Such apparently divergent results may be reconciled through the interaction of mechanisms related to microbial physiology, $\mathrm{C}$ turnover and $\mathrm{C}$ stabilization, but so far these interactions are poorly studied in subsoils. In particular, microbial dynamics related to subsoil C sequestration may depend on abiotic and biotic soil properties, including nutrient availability, which need to be better understood.

In the present laboratory study, we mimicked labile organic $\mathrm{C}$ input to a temperate agricultural sandy loam soil down to $300 \mathrm{~cm}$ depth using a simple, versatile substrate (glucose), which can be mineralized by the majority of heterotrophic microorganisms (Baldock and Oades, 1989; Hill et al., 2008). We tested the role of N, P and S availability on C mineralization, microbial physiology, and soil structural stability (clay dispersibility). The aim was to pursue whether different nutrient availability would link to an effect on microbial metabolism and soil properties, which could lead to divergent subsoil development and resultant conditions for $\mathrm{C}$ sequestration.

\section{Materials and methods}

\subsection{Soil sampling and characterization}

Soil was sampled in December 2015 from an excavated soil profile $(0-300 \mathrm{~cm})$ under an unfertilized temperate grass field at Foulumgaard Experimental Station, Aarhus University, Denmark ( $\left.56^{\circ} 29^{\prime} \mathrm{N}, 9^{\circ} 34^{\prime} \mathrm{E}\right)$. The soil was a sandy loam, classified as Typic Hapludult, with an upper black Ap horizon $(0-40 \mathrm{~cm})$ overlaying a slightly weathered $\mathrm{Bw}_{1}$ horizon $(40-70 \mathrm{~cm})$ and a $\mathrm{Bw}_{2}$ horizon showing signs of clay accumulation $(70-100 \mathrm{~cm})$. The lower part of the soil profile was a rather uniform clayey C horizon $(100-300 \mathrm{~cm})$. The B and C horizons were light brown without visual signs of redox interphases related to anoxic conditions (such as pseudogleys). Fragments of roots were seen in the Ap and $\mathrm{Bw}_{1}$ horizons. Soils were sampled at 20,60,100 and $300 \mathrm{~cm}$ depth from three sides of the excavated profile walls and pooled to cover smallscale heterogeneity. The soils were air dried, sieved $(<2 \mathrm{~mm})$, and stored at $2{ }^{\circ} \mathrm{C}$ until use. Chemical, physical and biological properties of the soil horizons are shown in Table 1.

\subsection{Carbon turnover at different C:N:P:S stoichiometry}

Carbon turnover to $\mathrm{CO}_{2}$ was measured in an automated set-up with 50 -g soil samples (dry wt basis) incubated at $40 \%$ water holding capacity (WHC) by adding appropriate volumes of water or nutrient solutions. Seven treatments were prepared with different ratios of added $\mathrm{C}, \mathrm{N}, \mathrm{P}$, and $\mathrm{S}$ from autoclaved solutions of glucose (2.5 mg glucose $\mathrm{Cg}^{-1}$ soil), $\mathrm{KNO}_{3}, \mathrm{KH}_{2} \mathrm{PO}_{4}$, and $\mathrm{K}_{2} \mathrm{SO}_{4}$ in demineralized (dem) water. The seven treatments represented amendments with (i) dem water as reference (Ref), (ii) glucose (Glu), (iii) glucose plus $P$ and $S$ at a C:P:S ratio of 100:1:1 (Glu + PS), (iv) glucose plus N at a C:N ratio of 10 (Glu + CN10), and glucose plus N, P and S at three different C:N:P:S ratios of (v) 100:10:1:1 (Glu + PS + CN10), (vi) 100:5:1:1 (Glu + PS + CN20), and (vii) 100:1.67:1:1 (Glu + PS + CN60). Nutrient solutions were mixed in appropriate stoichiometry for each treatment, $\mathrm{pH}$ was adjusted to native soil $\mathrm{pH}$ (Table 1 ), and after autoclaving $\left(121^{\circ} \mathrm{C}, 30 \mathrm{~min}\right)$ the solutions were added dropwise to soil conditioned in $100-\mathrm{cm}^{3}$ steel rings. Three treatment replicates were prepared for each soil horizon (i.e., 84 soil 
incubations in total).

For automated $\mathrm{CO}_{2}$ measurement, the soil samples were randomized and transferred to respirometer jars $(0.5 \mathrm{~L})$ that were incubated in a water bath at $20^{\circ} \mathrm{C}$ in a RESPICOND VI respirometer (A. Nordgren Innovations $\mathrm{AB}$, Bygdeå, Sweden). Each respirometer jar was equipped with a container holding $20 \mathrm{~mL}$ of $0.6 \mathrm{M} \mathrm{KOH}$ for trapping $\mathrm{CO}_{2}$ evolved from the soil. Decrease in the conductance of the $\mathrm{KOH}$ solution (reflecting $\mathrm{CO}_{2}$ uptake) was read hourly with platinum electrodes (Nordgren, 1988) during an incubation period of 42 days. The $\mathrm{KOH}$ solution was renewed when it was $50-60 \%$ saturated with $\mathrm{CO}_{2}$. The net $\mathrm{C}$ loss from soil samples was calculated as the difference between $\mathrm{CO}_{2}-\mathrm{C}$ trapped in jars with and without soil. Soil moisture contents were not adjusted, but remained at 35-38\% WHC during incubation. For each nutrient treatment and soil horizon, cumulative $\mathrm{C}$ losses induced by added glucose with or without nutrients were corrected for basal soil respiration, but included potential priming effects (Kuzyakov, 2010).

After the incubation period, each soil sample $(n=84)$ was homogenized for analyses of remaining labile (residual) glucose content, enzyme activity, microbial metabolic diversity, and clay dispersibility. These assays were done within 2 weeks of soil storage at $2{ }^{\circ} \mathrm{C}$ except for remaining labile glucose that was measured after 5 weeks.

\subsection{Remaining labile glucose}

Remaining labile glucose was extracted from $2 \mathrm{~g}$ soil in $10 \mathrm{~mL}$ dem water by horizontal shaking ( $10 \mathrm{~min}, 150 \mathrm{rev} \mathrm{min}^{-1}$ ) followed by centrifugation $(10 \mathrm{~min}, 4000 \mathrm{~g})$ and filtration $(0.45 \mu \mathrm{m})$. Aliquots of $1 \mathrm{~mL}$ supernatant (or diluted supernatant) were transferred to 10 -mL test tubes for immediate enzymatic quantification of glucose by reaction with $2 \mathrm{~mL}$ of an assay reagent with glucose oxidase, peroxidase, and $o$ dianisidine dihydrochloride (GAGO-20; Sigma). After incubation for $30 \mathrm{~min}$ at $37^{\circ} \mathrm{C}$ (water bath), the reaction was stopped by adding $2 \mathrm{~mL}$ of $6 \mathrm{M} \mathrm{H}_{2} \mathrm{SO}_{4}$ and mixing thoroughly. Absorbance was measured at $540 \mathrm{~nm}$ (Spectronic Helios Alpha, Thermo Scientific) for quantification of oxidized o-dianisidine by reference to a standard curve prepared from glucose concentrations of $0-16 \mu \mathrm{gL}^{-1}$. Extractions and assays were carried out in duplicate for each soil sample and remaining labile glucose contents were calculated after subtraction of (minor) colorimetric background of reference soils for each soil horizon.

\subsection{Enzyme activity and microbial metabolic diversity}

Enzymatic $\beta$-glucosidase activity was determined as an indicator of microbial parameters involved in $\mathrm{C}$ cycling in response to nutrient addition (Chen et al., 2017). The assay was done with 1-g soil samples amended with $4 \mathrm{~mL}$ modified universal buffer (MUB, $\mathrm{pH} 6$ ) and $1 \mathrm{~mL} p$ nitrophenyl- $\beta$-D-glucoside $(25 \mathrm{mM})$ according to Eivazi and Tabatabai (1988). Samples were incubated horizontally at $150 \mathrm{rev} \mathrm{min}^{-1}$ for $2 \mathrm{~h}$ at $20^{\circ} \mathrm{C}$. The reaction was stopped by adding $4 \mathrm{~mL}$ TRIS buffer ( $\mathrm{pH} 12$ ) and $1 \mathrm{~mL} \mathrm{CaCl}$, followed by centrifugation (10 min, $4000 \mathrm{~g}$ ). Absorbance of the supernatant was measured spectrophotometrically at $400 \mathrm{~nm}$ for quantification of released p-nitrophenol (NP). Three 1-g samples were used per soil analysis; two for assays as described above and one for determination of colorimetric background.

Microbial metabolic diversity was determined as community level profiles of C source utilization (CSU) assayed by MicroResp (Campbell et al., 2003). This was done using 96-well microplates (Fisher Scientific) with $0.4 \mathrm{~g}$ topsoil or $0.5 \mathrm{~g}$ subsoil $(60,100$, and $300 \mathrm{~cm})$ in each 1.2-mL deep-well. Nine C substrates (and dem water as reference) were included in the assay: D-glucose, D-galactose, $N$-acetyl glucosamine, Lglutamine, $\gamma$-aminobutyric acid, $\alpha$-ketoglutaric acid, L-malic acid, 4hydroxybenzoate, and lignin (all from Sigma Aldrich, except 4-hydroxybenzoate from VWR). The C substrates were selected to represent carbohydrates, amino sugars, amino acids, carboxylic acids, and recalcitrant organic compounds of relevance for soil ecosystems (Brackin et al., 2013; R.E. Creamer et al., 2016). The substrates were added in $25-\mu \mathrm{L}$ aliquots from stock solutions prepared to deliver $30 \mathrm{mg}$ substrate $\mathrm{g}^{-1}$ soil water except for the less soluble 4-hydroxybenzoate and lignin that were prepared to deliver $7.5 \mathrm{mg}$ substrate $\mathrm{g}^{-1}$ soil water (Campbell et al., 2003). Final WHC in the soil samples was around 55\%. Each soil well was connected to a detection plate well containing solidified agar with $\mathrm{NaHCO}_{3}$ and a pH dye with dynamic color change by equilibrium with $\mathrm{CO}_{2}$ (Campbell et al., 2003). The absorbance of the detector plate wells was measured $(570 \mathrm{~nm})$ in a microplate reader before and after $5 \mathrm{~h}$ of incubation (SPECTROstar Nano, BMG LABTECH). Readings of detector plates were converted to headspace $\mathrm{CO}_{2}$ concentrations by reference to a calibration curve prepared from detector plate wells equilibrated with specified $\mathrm{CO}_{2}$ concentrations as verified by gas chromatography using an Agilent 7890 GC system (Agilent, Nærum, Denmark) configured as previously described (Petersen et al., 2012). Four replicate MicroResp assays were performed for each soil sample; subsequent statistical analyses were based on the means of these four assays.

\subsection{Clay dispersibility}

Clay dispersibility was analysed by gently transferring 10-g soil samples (dry wt basis) and $80 \mathrm{~mL}$ of artificial rainwater $\left(12 \mu \mathrm{M} \mathrm{CaCl}_{2}\right.$, $15 \mu \mathrm{M} \mathrm{MgCl}_{2}$, and $121 \mu \mathrm{M} \mathrm{NaCl}$; $\mathrm{pH} 7.82$, EC $2.24 \mathrm{mS} \mathrm{m}^{-1}$ ) to $125 \mathrm{~mL}$ plastic bottles. The bottles were rotated end-over-end for $2 \mathrm{~min}$ (33 rev $\mathrm{min}^{-1}, 23-\mathrm{cm}$ diameter rotation). After rotation, the bottles were left for sedimentation for $230 \mathrm{~min}$, after which the top $60 \mathrm{~mL}$ of the suspension was gently transferred to $100-\mathrm{mL}$ glass beakers using a pipette. Under magnetic stirring, two individual 10-mL subsamples of this suspension were transferred to pre-weighed glass vials for weighing the mass of dispersed clay after oven-drying at $110^{\circ} \mathrm{C}$ for $48 \mathrm{~h}$.

A control experiment was performed to test for potential chemical effects of nutrient solutions on clay dispersibility. This was done with subsoil $(100 \mathrm{~cm})$ subjected to the treatments Ref, Glu + PS, $\mathrm{Glu}+\mathrm{CN10}$, and Glu + PS + CN10. Soil was conditioned in 100-cm ${ }^{3}$ rings $(n=3)$, amended with the respective nutrient solutions, and analysed for clay dispersibility after $5 \mathrm{~h}$ of incubation (equilibration) at $20^{\circ} \mathrm{C}$.

\subsection{Data analyses}

For CSU responses, the substrate richness $(S)$ for each nutrient treatment and soil horizon was rated as the number of substrates where $\mathrm{CO}_{2}$ production exceeded a threshold value defined as the mean $+2 \times$ standard deviation $(n=3)$ of the $\mathrm{CO}_{2}$ production from reference soil wells without added substrates (but dem water only). A functional diversity index (Shannon-Weaver index, $H$ ) was calculated as $-\Sigma p_{i} \ln p_{i}$, where $p_{i}$ is the ratio of the $\mathrm{CO}_{2}$ production of each substrate to the sum of the $\mathrm{CO}_{2}$ production from all substrates (Zak et al., 1994). In this analysis, the $\mathrm{CO}_{2}$ production from substrates utilized was corrected for the mean $\mathrm{CO}_{2}$ production of the reference wells; $\mathrm{CO}_{2}$ production below the threshold values (defined above) was set to zero.

For glucose turnover and clay dispersibility, the effects of nutrient treatment and soil horizon were evaluated by two-way analysis of variance (ANOVA). For the CSU indices, $S$ and $H$, the effect of nutrient treatment was tested for each soil horizon by one-way ANOVA. When the treatment or soil horizon effect was significant $(P<0.05)$, post hoc pairwise comparisons were made using the Newman-Keuls test (Zar, 2010) in SigmaPlot version 11.0 (Systat Software, Inc.).

The multivariate patterns of CSU responses among soil horizons and among nutrient treatments within the same soil horizon were analysed with principal component analysis (PCA) using the LatentiX software version 2.13 (LatentiX Aps, Copenhagen, Denmark). Data were autoscaled prior to PCA analysis (von den Berg et al., 2006). 


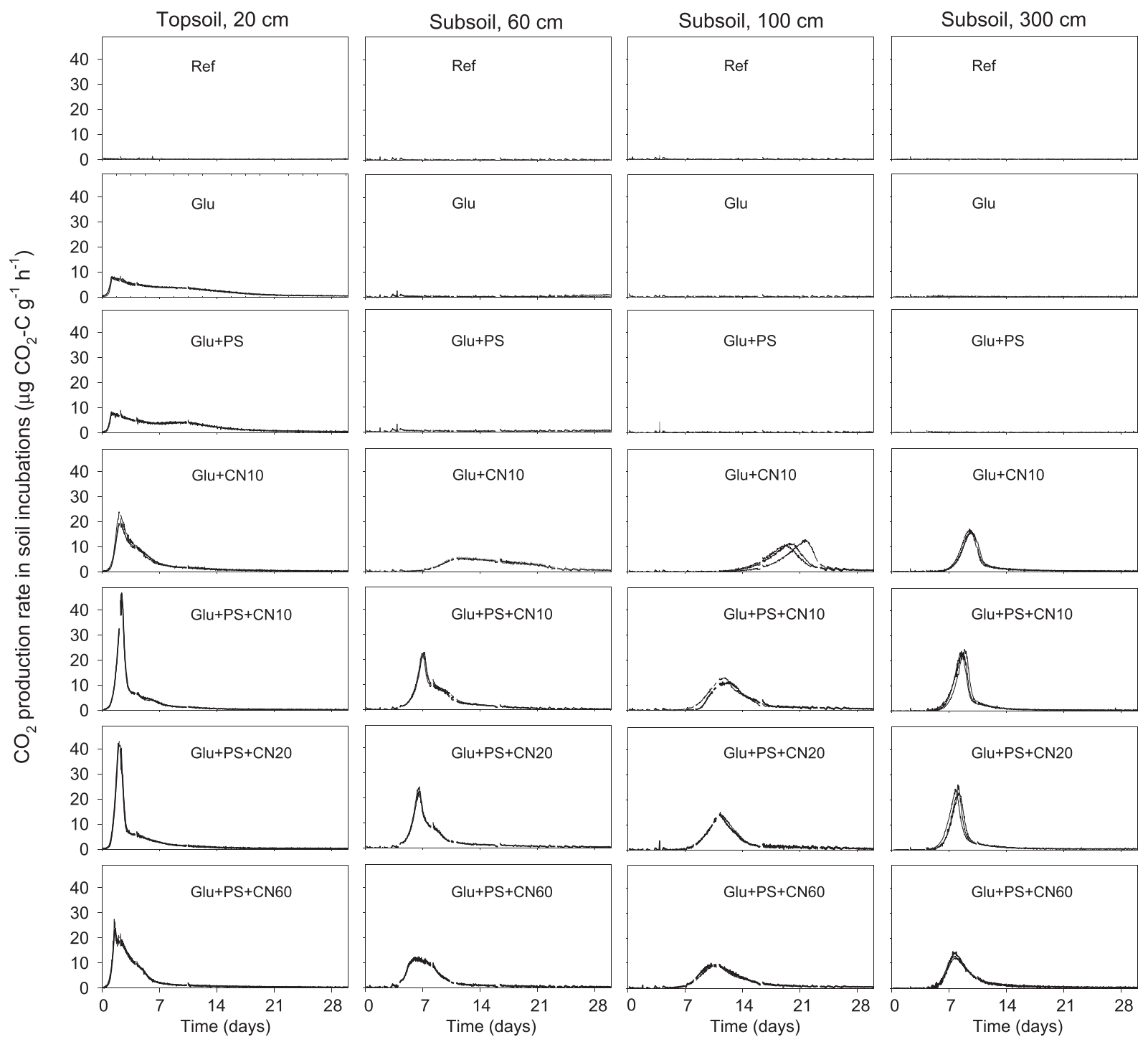

Fig. 1. Rates of $\mathrm{CO}_{2}$ production in topsoil $(20 \mathrm{~cm})$ and subsoils $(60,100$ and $300 \mathrm{~cm})$ in treatments with glucose and nutrients at different C:N:P:S stoichiometry. Data are shown for individual replicates $(n=3)$ during 30 days of a 42-day incubation period. Treatments: Ref, reference; Glu, glucose; Glu + PS, glucose plus P and S at a C:P:S ratio of 100:1:1; Glu + CN10, glucose plus N at a C:N ratio of 10; Glu + PS + CN10, Glu + PS + CN20, and Glu + PS + CN60, glucose plus N, P and S at C:N:P:S ratios of 100:10:1:1, 100:5:1:1, and 100:1.67:1:1, respectively.

\section{Results}

\subsection{Rates and dynamics of $\mathrm{CO}_{2}$ production}

Carbon dioxide production rates from SOC mineralization in topsoil reference treatments were consistently low during the incubation period, with a mean basal respiration rate of $0.15 \mu \mathrm{g} \mathrm{Cg}^{-1}$ soil h$^{-1}$ (Fig. 1). In subsoils, reference mineralization rates were likewise consistently low with means of $0.06 \mu \mathrm{g} \mathrm{Cg}{ }^{-1}$ soil h$^{-1}$ for the deepest soil horizon (Fig. 1).

Adding glucose with different nutrient supplements resulted in divergent mineralization dynamics in topsoil and subsoils. In topsoil, all glucose treatments caused immediate stimulation of $\mathrm{CO}_{2}$ production (i.e., within hours) and maximum respiration rates were recorded after 1-2 days of incubation. Highest stimulation was caused by $\mathrm{Glu}+\mathrm{PS}+\mathrm{CN} 10$ and Glu + PS + CN20 (maximum rates of 46.9 and $40.2 \mu \mathrm{g} \mathrm{C} \mathrm{g}^{-1}$ soil h$^{-1}$, respectively), whereas lowest stimulation was caused by Glu and Glu + PS ( 8.3 and $8.6 \mu \mathrm{g} \mathrm{Cg}^{-1}$ soil h$^{-1}$, respectively). In subsoils, glucose also stimulated $\mathrm{CO}_{2}$ production, but only after longer lag-phases (4-13 days) and only in treatments with concurrent $\mathrm{N}$ amendment. This indicated that glucose was not mineralized in subsoil treatments with Glu and Glu + PS, whereas the highest rates were obtained by $\mathrm{Glu}+\mathrm{PS}+\mathrm{CN} 10$ and $\mathrm{Glu}+\mathrm{PS}+\mathrm{CN} 20$ (12.2-24.3 $\mu \mathrm{g} \mathrm{C} \mathrm{g}^{-1}$ soil $^{-1}$ ). After the peaks of glucose turnover rates, $\mathrm{CO}_{2}$ production in all nutrient treatments and soil horizons decreased to background levels within 1-2 weeks.

\subsection{Cumulative carbon losses and retention}

In topsoil, the cumulative $\mathrm{CO}_{2}$ losses corresponded to $71-77 \%$ of the added glucose $\mathrm{C}$ without significant difference among the nutrient treatments (Fig. 2a). In subsoils, the corresponding $\mathrm{CO}_{2}$ losses were $50-75 \%$ in the presence of added N (Fig. 2a), but only $1-17 \%$ in the absence of added N (i.e., Glu and Glu + PS). Further, in the absence of added $\mathrm{N}$, the cumulative $\mathrm{CO}_{2}$ losses decreased with soil depth in accordance with the decrease in native soil $\mathrm{TN}$ concentrations (Table 1). Addition of PS together with N (Glu + PS + CN10) contributed to moderate increase $(\sim 1.2$ fold) in cumulative C losses (cf. Glu + CN10).

Remaining labile glucose contents, as measured in the soil after 42 days, aligned with the pattern of cumulative $C$ losses, i.e., with no 


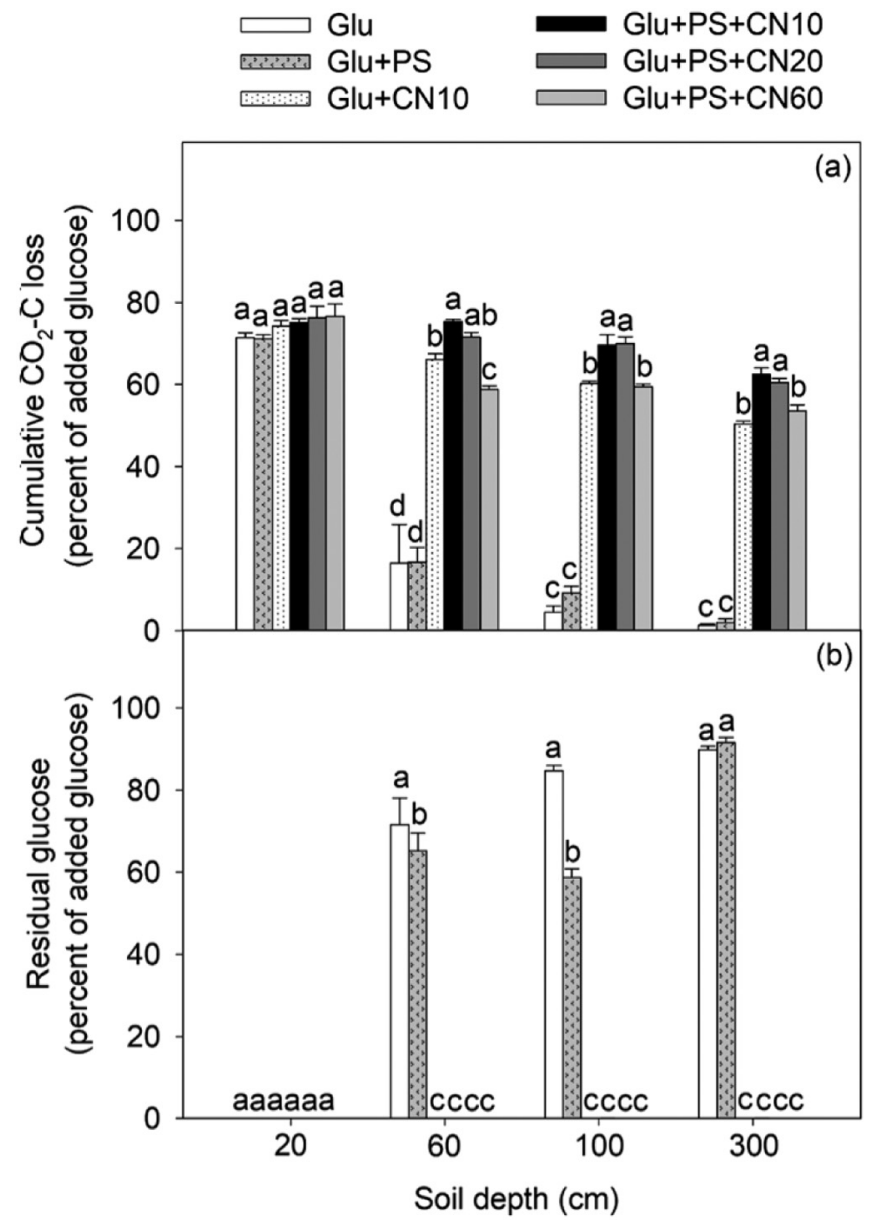

Fig. 2. (a) Cumulative $\mathrm{CO}_{2}-\mathrm{C}$ loss and (b) remaining labile (residual) glucose content in topsoil $(20 \mathrm{~cm})$ and subsoils $(60,100$, and $300 \mathrm{~cm})$ after incubation for 42 days with glucose and nutrients at different C:N:P:S stoichiometry. Data are mean and standard error $(n=3)$ with letters indicating significant differences $(P<0.05)$ between treatments within the same soil depth. Treatments: Glu, glucose; Glu + PS, glucose plus P and S at a C:P:S ratio of 100:1:1; $\mathrm{Glu}+\mathrm{CN} 10$, glucose plus $\mathrm{N}$ at a C:N ratio of 10; Glu + PS + CN10, $\mathrm{Glu}+\mathrm{PS}+\mathrm{CN} 20$, and Glu + PS + CN60, glucose plus N, P and S at C:N:P:S ratios of 100:10:1:1, 100:5:1:1, and 100:1.67:1:1, respectively.

Table 2

Net retained carbon (C) calculated from added $\mathrm{C}$ minus produced $\mathrm{CO}_{2}$ and recovered glucose in topsoil $(20 \mathrm{~cm})$ and subsoils $(60,100$, and $300 \mathrm{~cm})$ after incubation for 42 days at different C:N:P:S stoichiometry. Data are mean and standard error $(n=3)$ with letters indicating significant differences $(P<0.05)$ between treatments within the same soil depth. Treatments: Glu, glucose; Glu + PS, glucose plus P and S at a C:P:S ratio of 100:1:1; Glu + CN10, glucose plus $\mathrm{N}$ at a C:N ratio of $10 ; \mathrm{Glu}+\mathrm{PS}+\mathrm{CN} 10$, Glu + PS + CN20 and Glu + PS + CN60, glucose plus N, P and S at C:N:P:S ratios of 100:10:1:1, 100:5:1:1, and 100:1.67:1:1, respectively.

\begin{tabular}{lllll}
\hline \multirow{2}{*}{ Treatment } & \multicolumn{4}{l}{ C retention (\% of added glucose C) } \\
\cline { 2 - 5 } & $20 \mathrm{~cm}$ & $60 \mathrm{~cm}$ & $100 \mathrm{~cm}$ & $300 \mathrm{~cm}$ \\
\hline Glu & $29 \pm 1 \mathrm{a}$ & $12 \pm 8 \mathrm{~d}$ & $11 \pm 1 \mathrm{c}$ & $9 \pm 1 \mathrm{c}$ \\
Glu + PS & $29 \pm 1 \mathrm{a}$ & $18 \pm 4 \mathrm{~d}$ & $32 \pm 2 \mathrm{~b}$ & $6 \pm 1 \mathrm{c}$ \\
Glu + CN10 & $26 \pm 1 \mathrm{a}$ & $34 \pm 1 \mathrm{~b}$ & $40 \pm 1 \mathrm{a}$ & $50 \pm 1 \mathrm{a}$ \\
Glu + PS + CN10 & $25 \pm 1 \mathrm{a}$ & $25 \pm 0 \mathrm{c}$ & $30 \pm 1 \mathrm{~b}$ & $38 \pm 1 \mathrm{~b}$ \\
Glu + PS + CN20 & $24 \pm 2 \mathrm{a}$ & $28 \pm 1 \mathrm{bc}$ & $30 \pm 1 \mathrm{~b}$ & $39 \pm 1 \mathrm{~b}$ \\
Glu + PS + CN60 & $23 \pm 2 \mathrm{a}$ & $41 \pm 1 \mathrm{a}$ & $41 \pm 1 \mathrm{a}$ & $46 \pm 1 \mathrm{a}$ \\
\hline
\end{tabular}

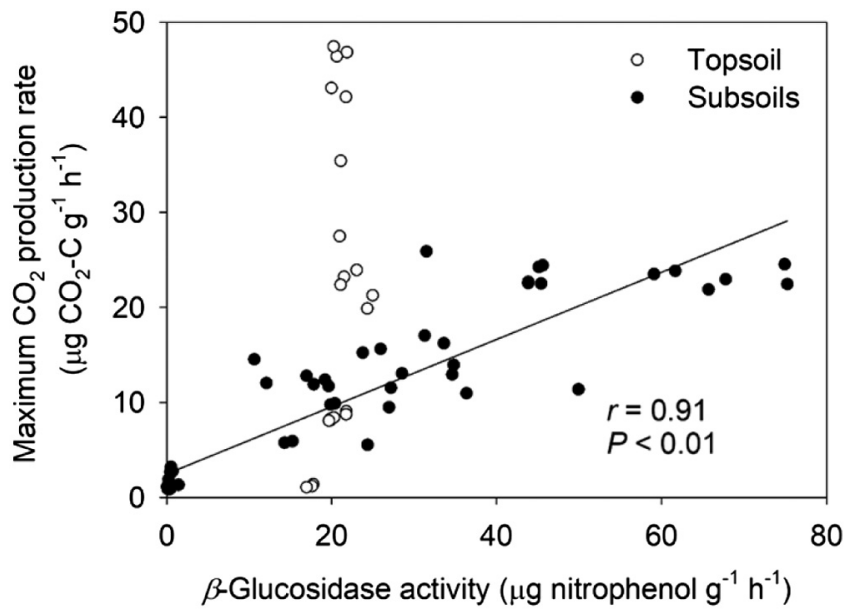

Fig. 3. Correlation between maximum $\mathrm{CO}_{2}$ production rate during incubation and $\beta$-glucosidase activity after incubation for 42 days in topsoil $(20 \mathrm{~cm}$; white symbols) and subsoils (60, 100 and $300 \mathrm{~cm}$; black symbols) treated with glucose and nutrients at different C:N:P:S stoichiometry. The correlation was significant for subsoils (line and correlation shown), but not for topsoil ( $r=0.38$, $P=0.09$ ).

residual glucose in topsoil and in subsoil treatments with added $\mathrm{N}$ (Fig. 2b). However, in subsoil treatments without added N, 59-92\% of the nominally added glucose was chemically recovered after the incubation period (Fig. 2b).

Tentative mass balances of added $\mathrm{C}$ minus trapped $\mathrm{CO}_{2}$ and recovered glucose $\mathrm{C}$ indicated that the net $\mathrm{C}$ retained in topsoil was $23-29 \%$ of the added (Table 2), likely stabilized through microbial anabolism. The size of this net stabilized $\mathrm{C}$ pool was more variable in subsoils (Table 2) with a mean of $37 \%$ in treatments with added $\mathrm{N}$ and $15 \%$ in treatments without added N. Yet, among the treatments with added $\mathrm{N}$, the relatively nutrient-poorer $\mathrm{Glu}+\mathrm{CN} 10$ and $\mathrm{Glu}+\mathrm{PS}+\mathrm{CN} 60$ treatments resulted in higher estimates of net retained $\mathrm{C}$ as compared to the more nutrient balanced treatments $\mathrm{Glu}+\mathrm{PS}+\mathrm{CN} 10$ and Glu + PS + CN20 (Table 2).

\subsection{Enzyme activity}

The $\beta$-glucosidase activity in reference treatments after the 42 day incubation period (Fig. S1) was $>20$-fold higher in topsoil $\left(17.4 \mu \mathrm{g} \mathrm{NP} \mathrm{g}^{-1} \mathrm{~h}^{-1}\right)$ than in subsoil $\left(<0.7 \mu \mathrm{g} \mathrm{NPg}^{-1} \mathrm{~h}^{-1}\right)$, which aligned with enzyme activities in the native soil profile (Table 1 ). As compared to reference treatments, the $\beta$-glucosidase activity in topsoil with glucose and nutrient amendments was increased by 15-38\% (Fig. $\mathrm{S} 1)$. In subsoils, glucose without $\mathrm{N}$ amendment failed to stimulate $\beta$ glucosidase activity, whereas treatments with $\mathrm{N}$ amendment showed a pronounced increase in enzyme activity (Fig. S1), with highest stimulation for Glu + PS + CN10 treatment. Correlation analyses (Fig. 3) showed that the resulting $\beta$-glucosidase activity in subsoils after the 42 day incubation period was strongly correlated $(r=0.91 ; P<0.01)$ to the maximum $\mathrm{CO}_{2}$ production rate during incubation. Such strong correlation was absent in topsoil $(r=0.38 ; P=0.09)$, where $\beta$-glucosidase activity was only weakly stimulated during incubation (Fig. 3).

\subsection{Microbial metabolic diversity}

In general, all nine $\mathrm{C}$ substrates in MicroResp were utilized by the microbial communities in topsoil treatments (i.e., $S=8-9$ ), whereas varying substrate utilization was found in subsoil depending on the 


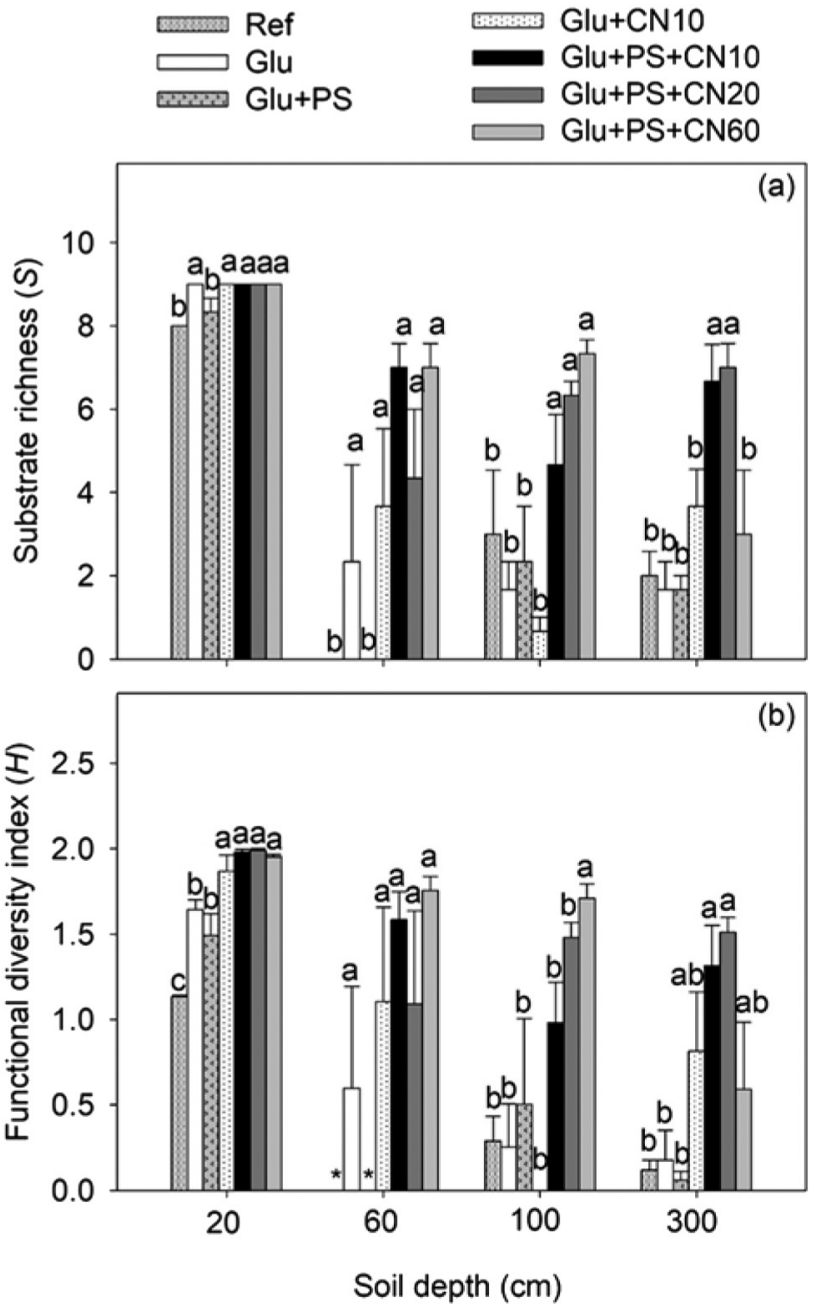

Fig. 4. (a) Substrate richness $(S)$ and (b) Shannon-Weaver diversity index $(H)$ of carbon source utilization in topsoil $(20 \mathrm{~cm})$ and subsoils $(60,100$ and $300 \mathrm{~cm})$. Utilization of nine divergent carbon sources was assayed with soil from treatments incubated 42 days with glucose and nutrients at different C:N:P:S stoichiometry. Data are mean and standard error $(n=3)$ with letters indicating significant differences $(P<0.05)$ between treatments within the same soil depth. Asterisks shown in panel b indicate that $H$ was not calculated when $S$ was zero. Treatments: Ref, reference; Glu, glucose; Glu + PS, glucose plus P and $\mathrm{S}$ at a C:P:S ratio of 100:1:1; Glu + CN10, glucose plus $\mathrm{N}$ at a C:N ratio of 10; $\mathrm{Glu}+\mathrm{PS}+\mathrm{CN} 10$, Glu + PS + CN20, and Glu + PS + CN60, glucose plus N, P and $S$ at C:N:P:S ratios of 100:10:1:1, 100:5:1:1, and 100:1.67:1:1, respectively.

precedent nutrient treatments (Fig. 4a). Substrate richness in subsoils was highest $(S=3-7)$ in treatments combining $\mathrm{N}, \mathrm{P}$ and $\mathrm{S}$, whereas it was zero in reference treatments, and low in treatments without added $\mathrm{N}(S=0-2)$. Further, none of the subsoil treatments showed positive mineralization response to lignin. The pattern of functional diversity $(H)$ aligned with the pattern of substrate richness (Fig. 4b), substantiating a high metabolic diversity in topsoil and weaker diversity in subsoils, though relatively high in treatments combining N, P and S. Overall, the subsoil substrate richness and functional diversity were highest in the two nutrient balanced treatments Glu + PS + CN10 and $\mathrm{Glu}+\mathrm{PS}+\mathrm{CN} 20$.

The pattern of CSU in topsoil and subsoil was differentiated by PCA with a primary component (PC 1) explaining $87 \%$ of the variation (Fig. S2). Separation of nutrient treatments in individual soil horizons was
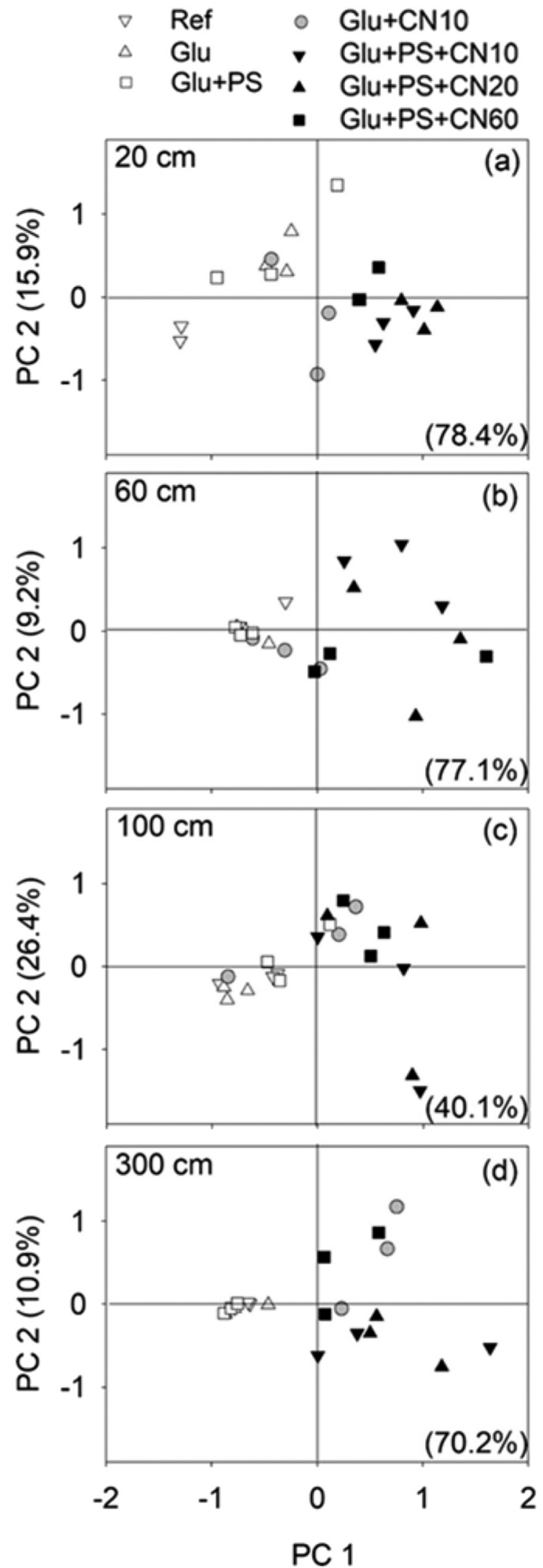

(caption on next page) 
Fig. 5. Score plots of principal component analysis of carbon source utilization in (a) topsoil $(20 \mathrm{~cm}$ ) and subsoil from (b) $60 \mathrm{~cm}$, (c) $100 \mathrm{~cm}$, and (d) $300 \mathrm{~cm}$. Utilization of carbon sources was assayed with soil from treatments incubated 42 days with glucose and nutrients at different C:N:P:S stoichiometry. Data are shown for individual replicates $(n=3)$ of each treatment. Numbers in parentheses represent the variation explained by the two principal components PC 1 and PC 2. Treatments: Ref, reference; Glu, glucose; Glu + PS, glucose plus P and $S$ at a C:P:S ratio of 100:1:1; Glu + CN10, glucose plus $\mathrm{N}$ at a C:N ratio of 10; Glu + PS + CN10, Glu + PS + CN20, and Glu + PS + CN60, glucose plus N, P and S at C:N:P:S ratios of 100:10:1:1, 100:5:1:1, and 100:1.67:1:1, respectively.

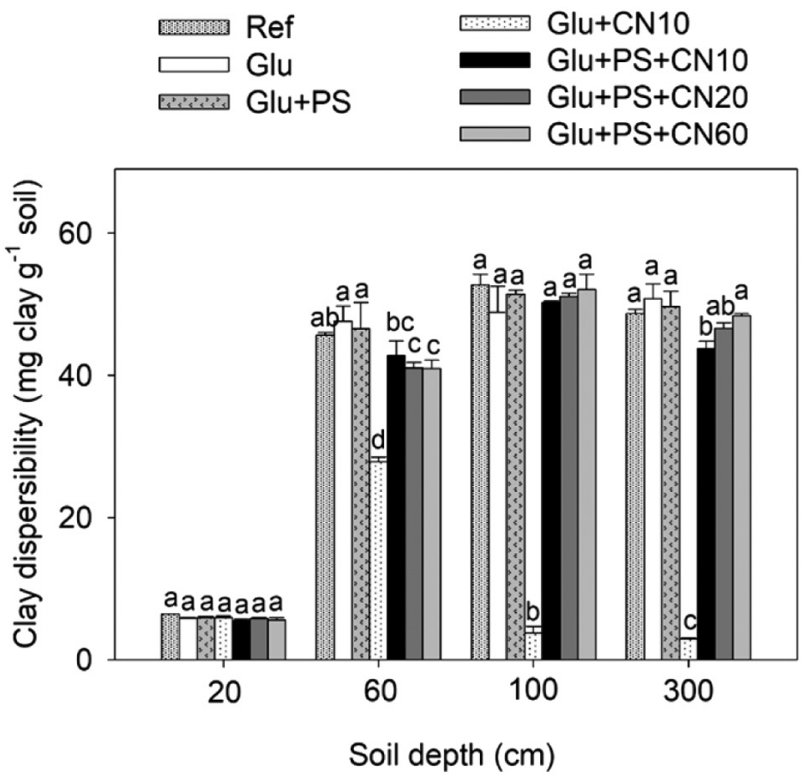

Fig. 6. Clay dispersibility in topsoil $(20 \mathrm{~cm})$ and subsoils $(60,100$, and $300 \mathrm{~cm})$ after incubation for 42 days with glucose and nutrients at different C:N:P:S stoichiometry. Data are mean and standard error $(n=3)$ with letters indicating significant differences $(P<0.05)$ between treatments within the same soil depth. Treatments: Ref, reference; Glu, glucose; Glu + PS, glucose plus P and S at a C:P:S ratio of 100:1:1; Glu + CN10, glucose plus $\mathrm{N}$ at a C:N ratio of 10 ; $\mathrm{Glu}+\mathrm{PS}+\mathrm{CN} 10$, Glu + PS + CN20, and Glu + PS + CN60, glucose plus N, P and $S$ at C:N:P:S ratios of 100:10:1:1, 100:5:1:1, and 100:1.67:1:1, respectively.

mainly related to the absence or presence of added N (Fig. 5). Further, in topsoil the Glu + CN10 treatment was separated from the three treatments combining N, P and S (Fig. 5a); yet, with increasing soil depth, this separation became increasingly weaker (Fig. 5b-d), suggesting an increasing role of $\mathrm{N}$ limitation with greater soil depth. It was found that the discriminatory (PC1) effects of all CSU substrates were similar (loading plots; Fig. S3) and thus not specifically related to presence of intramolecular $\mathrm{N}$ (present in three of the nine substrates); this was likely related to the short MicroResp assay time not facilitating microbial adaptation or growth responses.

\subsection{Clay dispersibility}

In topsoil reference treatments, the clay dispersibility was $6.4 \mathrm{mg} \mathrm{g}^{-}$ 1 , and no changes were imposed by the nutrient treatments after 42 days of incubation (Fig. 6). In subsoil reference treatments, the clay dispersibility was $46-53 \mathrm{mg} \mathrm{g}^{-1}$, and effects of nutrient treatments were moderate and often non-significant. However, the Glu + CN10 treatment was a notable exception. Here, subsoil clay dispersibility was much lower than in the other treatments, i.e., as low as $3-4 \mathrm{mg} \mathrm{g}^{-1}$ for subsoil from 100 to $300 \mathrm{~cm}$ (Fig. 6). Yet, interpretation of this result in terms of microbial effects was challenged by control experiments showing that treatments with Glu + CN10 and Glu + PS + CN10 also reduced clay dispersibility, even after a soil incubation time of only $5 \mathrm{~h}$ (Fig. S4). This suggested an immediate chemical effect of the Glu + CN10 and Glu + PS + CN10 treatments on clay dispersibility, whereas such a chemical effect was not mediated by the Glu + PS treatment (Fig. S4).

\section{Discussion}

\subsection{Nutrient limitation in subsoils}

The fastest mineralization of glucose in topsoil was observed in treatments combining N, P and S. Yet, the overall C losses after 42 days were similar among treatments with and without added nutrients, signifying sufficient native nutrient availability in the topsoil for full microbial glucose mineralization over time. This agree with results from previous studies where addition of $\mathrm{C}$ with nutrients $(\mathrm{N}$ or $\mathrm{P}$ ) to forest, fallow, or plantation soil significantly increased the maximum $\mathrm{CO}_{2}$ production rate without affecting the cumulative $\mathrm{CO}_{2}$ production after a sufficiently long incubation period (Heitkötter et al., 2017a; Meyer et al., 2017, 2018).

The dynamics of $\mathrm{C}$ mineralization in subsoils were largely controlled by nutrient availability, notably $\mathrm{N}$. The supplement of $\mathrm{N}$ $(\mathrm{Glu}+\mathrm{PS}+\mathrm{CN10})$ in addition to P and S (Glu + PS) increased the cumulative $C$ losses by $5-30$ fold (increasing with soil depth), whereas the supplement of $\mathrm{P}$ and $\mathrm{S}$ ( Glu $+\mathrm{PS}+\mathrm{CN} 10)$ in addition to $\mathrm{N}$ (Glu + CN10) increased the cumulative C losses merely by $\sim 20 \%$. This substantiates the potential importance of $\mathrm{N}$ limitation for $\mathrm{C}$ mineralization in subsoils (Fierer et al., 2003; Heitkötter et al., 2017b; Meyer et al., 2018).

Nitrogen limitation in subsoil was also reflected by microbial processes at the level below integral $\mathrm{CO}_{2}$ production. Addition of glucose and $\mathrm{N}$ increased $\beta$-glucosidase activity, which was positively correlated to the maximum $\mathrm{CO}_{2}$ production rate. Moreover, microbial metabolic diversity of CSU was mainly related to the absence or presence of added $\mathrm{N}$. Collectively, these results indicated that $\mathrm{N}$ addition plays a critical role in shaping microbial physiological responses related to turnover of labile C in subsoils. Previously, such links between $\mathrm{N}$ availability and microbial responses have mainly been traced in topsoils (Averill and Waring, 2017; Chen et al., 2017). Yet, in a study with chemically divergent root biomasses, Z. Liang et al. (unpublished data) likewise found that root $\mathrm{N}$ concentration affected root $\mathrm{C}$ mineralization and microbial dynamics in subsoils and that mineralization of residual root $\mathrm{C}$ was enhanced by added mineral $\mathrm{N}$.

In the absence of $\mathrm{P}$ and $\mathrm{S}$, treatments with glucose and $\mathrm{N}$ showed prolonged lag-phases before onset of stimulated mineralization and/or prolonged turnover time of glucose (Fig. 1), which could be related to retarded growth of microorganisms dependent on the production of exopolymers or exoenzymes for P and S mining (Fontaine et al., 2003; Heitkötter et al., 2017a). For example, as a starvation response to sulfate, soil microorganisms have previously been shown to increase the production of sulfonatases and sulfatases, which catalyse desulfonation of carbon-bonded sulfur and sulfate esters (Fitzgerald, 1976; Kertesz, 1999).

\subsection{Nutrient stoichiometry and carbon use efficiency in subsoils}

Added glucose was fully depleted in subsoils when $\mathrm{N}$ limitation was alleviated. According to the stoichiometric decomposition theory (e.g., Hessen et al., 2004), relatively more C may be incorporated into microbial biomass, rather than being respired to $\mathrm{CO}_{2}$, when nutrient availability meets the microbial demand (Hessen et al., 2004; Sinsabaugh et al., 2013). Therefore, it was expected that $\mathrm{CO}_{2}$ production would decrease with increasing and balanced nutrient availability in subsoil. However, the results indicated that the $\mathrm{CO}_{2}$ production was on average $17 \%$ higher in the nutrient balanced Glu + PS + CN10 and Glu + PS + CN20 treatments than in the relatively nutrient-poorer 
$\mathrm{Glu}+\mathrm{CN} 10$ or Glu + PS + CN60 treatments (Fig. 2a). This aligns with findings by Creamer et al. (2014) and C.A. Creamer et al. (2016), who showed that glucose-derived $\mathrm{CO}_{2}$ production increased significantly with nutrient addition in both sandy and clayey topsoils. In our study it could be hypothesized that microbial biomass derived from glucose in the nutrient balanced treatments was higher at an earlier stage of incubation, but that the biomass was subsequently decomposed eventually releasing $\mathrm{CO}_{2}$ (Van Veen et al., 1985). Alternatively, the results could be linked to development of microbial community structures with different $C$ use efficiency under different nutrient conditions, for example related to increased $\mathrm{C}$ investment in production and release of extracellular compounds for mining of deficient nutrients (Kertesz, 1999; Fontaine et al., 2003; Sinsabaugh et al., 2013; Chen et al., 2014). Although speculative, these mechanisms would align with comparatively lower $\mathrm{CO}_{2}$ production in the relatively nutrient poorer Glu + CN10 and Glu + PS + CN60 treatments in the subsoils. Yet, with the present data, no clear differentiation could be made between effects related microbial growth and $\mathrm{C}$ mineralization.

\subsection{Nutrient availability and subsoil carbon sequestration}

Enhancing subsoil organic C storage is suggested to have importance for climate change mitigation (Lorenz and Lal, 2005; Kell, 2011; Lynch and Wojciechowski, 2015). However, labile organic C entering subsoils, such as root exudates by deep rooted crops, may eventually result in $\mathrm{CO}_{2}$ efflux due to mineralization by microorganisms. Still, as demonstrated here, and substantiated in other studies (Fierer et al., 2003; Heitkötter et al., 2017b; Meyer et al., 2018), subsoil $\mathrm{N}$ limitation of microbial activity and $\mathrm{C}$ turnover may allow prolonged persistence of easily decomposable C. Since low N concentration is a common property in many subsoil ecosystems (Fierer et al., 2003; Jia et al., 2017; Tian et al., 2016), this could be a general mechanism related to $\mathrm{C}$ retention in subsoils. Nevertheless, stabilization of SOC on decadal to centurial time scales is believed largely to be linked to physical protection of remains of $\mathrm{C}$ compounds resulting from microbial growth and anabolism (Cotrufo et al., 2013; Liang et al., 2017). In this way, stabilization of SOC may paradoxically depend on $\mathrm{CO}_{2}$ losses, which result from the use of organic $\mathrm{C}$ as electron donor in the energy metabolism coupled to anabolism in aerobic and anaerobic heterotrophs.

Kirkby et al. (2013, 2014) showed that combined supplementary nutrients (N, P and S) increased the formation of stable SOC when fresh $\mathrm{C}$ was incorporated into topsoils from varying agro-ecological regions in Australia. It was argued that the conservative use of fertilizers in modern farming systems may unintentionally limit the supply of nutrients for microbial growth and stable C formation, which could explain why SOC in some agricultural soils increases less than expected from the amounts of returned C-rich residues (Kirkby et al., 2014). Thus, to increase stable C formation, Kirkby et al. (2013) suggested that nutrients could be added to stubbles before their post-harvest incorporation to soil according to the C:N:P:S stoichiometry of humus. Whereas such nutrient addition could increase subsoil C stabilization, our study additionally indicated that a moderately higher content of retained $\mathrm{C}$ could form under relatively nutrient-poor as compared to more nutrient balanced conditions. This could potentially be attributed to microbial adaptation and responses to conditions not fully alleviating nutrient limitation (discussed in Section 4.2), with extracellular C investments eventually contributing to the stable $\mathrm{C}$ pool. However, better understanding of the mechanisms regulating the fate of subsoil $\mathrm{C}$ in response to nutrient stoichiometry should be pursued in order to potentially predict the response of subsoil $\mathrm{C}$ sequestration for example in relation to anthropogenic addition of nutrients to topsoil. Likewise, future studies should include the use of labeled C substrates to quantify potential priming effects related to nutrient stimulation of subsoil SOC mineralization (Kuzyakov, 2010), which expectedly was low in the present subsoils where the SOC content was only $0.04-0.18 \%$. Such studies should also include soil types with other ranges of clay content and $\mathrm{pH}$, since microbial processes and the stabilization of microbial degradation products may also depend on soil properties. Finally, it should be realized that conclusions from laboratory incubation studies may well indicate potential processes and mechanisms, but may need to be substantiated by studies under in situ soil conditions.

\subsection{Effects of nutrient availability on subsoil clay dispersibility}

Extracellular organic compounds (e.g., polysaccharides) produced during microbial anabolic processes may bond soil minerals into differently sized organo-mineral complexes, which contribute to improved soil structure (Degens, 1997). Visually, soil samples after the 42 days incubation period showed signs of varying soil aggregation depending on the nutrient treatments. Therefore, we screened the different nutrient treatments for their potential to improve soil structure (tested as reduced clay dispersibility). The results showed a markedly lower clay dispersibility for the Glu + CN10 treatment than for the other treatments. At first, this indicated that presence of $\mathrm{N}$, but concurrent lack of $\mathrm{P}$ and $\mathrm{S}$, triggered a microbial response related to mechanisms of clay stabilization, such as production of exudates for $\mathrm{P}$ and $\mathrm{S}$ mining (Mooshammer et al., 2014; Richardson et al., 2011). Yet, a control experiment challenged this hypothesis as the same Glu + CN10 treatment resulted in very low clay dispersibility just after $5 \mathrm{~h}$ of incubation, thus pointing at chemical rather than biological mechanisms. This was confirmed when increasing levels of $\mathrm{KNO}_{3}\left(10-500 \mu \mathrm{g} \mathrm{N} \mathrm{g}^{-1}\right.$ soil) was added to subsoil that was immediately assayed for clay dispersibility; compared to reference treatments remarkable reductions in clay dispersibility of $78 \%$ and $96 \%$ were observed already for $\mathrm{KNO}_{3}$ levels of 10 and $50 \mu \mathrm{g} \mathrm{N} \mathrm{g}^{-1}$ soil, respectively (Z. Liang, unpublished data). Whereas this soil physical response may warrant further documentation, it was believed to result from interaction between $\mathrm{NO}_{3}{ }^{-}$and clay dispersibility. This could also explain why the response was seen both initially and after 42 days of incubation with the subsoil Glu + CN10 treatments (where $\mathrm{NO}_{3}{ }^{-}$may not have been depleted due to lack of $\mathrm{P}$ and $S$ ), but on the other hand the response was seen only initially (and not after 42 days) for the Glu $+\mathrm{PS}+\mathrm{CN} 10$ treatment, where $\mathrm{NO}_{3}{ }^{-}$ expectedly was depleted during the 42 days incubation in accordance with the extensive glucose mineralization (Figs. 6 and S4). It remained uncertain, therefore, to what extent the $\mathrm{N}$-stimulated microbial activity in the present study contributed to soil structural changes in the subsoil. Hence, we encourage further studies focusing on the interactions between biochemical and physical mechanisms of subsoil C stabilization.

\section{Conclusions}

This work focused on the fate and effects of labile $\mathrm{C}$ in a temperate sandy loam subsoil in relation to different nutrient availability of N, P, and $\mathrm{S}$. Our results from laboratory incubations suggest that $\mathrm{N}$ availability is a key factor controlling labile subsoil $\mathrm{C}$ mineralization to $\mathrm{CO}_{2}$. We have shown that glucose amendments with $\mathrm{P}$ and $\mathrm{S}$, but deficient in $\mathrm{N}$, resulted in weak stimulation of subsoil $\mathrm{C}$ mineralization and subsequent chemical recovery of $59-92 \%$ of added glucose even after 42 days. Yet, when $\mathrm{N}$ was added together with $\mathrm{P}$ and $\mathrm{S}$, the $\mathrm{CO}_{2}$ production significantly increased and glucose was fully depleted. Analysis of microbial responses to subsoil $\mathrm{C}$ and nutrient availability substantiated that increased $\mathrm{N}$ availability was linked to increased enzyme activity and increased microbial metabolic diversity. Future studies should substantiate the role of nutrient availability for dynamics of subsoil microbial processes (e.g., related to production of extracellular exudates) and the resulting change in soil structure that may contribute to long-term subsoil C sequestration.

\section{Declarations of interest}

None. 


\section{Acknowledgements}

We thank Karin Dyrberg, Bodil Stensgaard, and Margit Paulsen for skilled assistance in laboratory work. We also thank Lars J. Munkholm for discussions on clay dispersibility and two journal reviewers for valuable comments. This work was supported by the Deep Frontier project funded by the Villum Foundation.

\section{Appendix A. Supplementary data}

Supplementary data to this article can be found online at https:// doi.org/10.1016/j.geoderma.2018.08.021.

\section{References}

Averill, C., Waring, B., 2017. Nitrogen limitation of decomposition and decay: how can it occur? Glob. Chang. Biol. 24, 1417-1427.

Baldock, J., Oades, J., 1989. Effect of electrolyte concentration on glucose decomposition in soil. Soil Res. 27, 433-438.

Brackin, R., Robinson, N., Lakshmanan, P., Schmidt, S., 2013. Microbial function in adjacent subtropical forest and agricultural soil. Soil Biol. Biochem. 57, 68-77.

Campbell, C.D., Chapman, S.J., Cameron, C.M., Davidson, M.S., Potts, J.M., 2003. A rapid microtiter plate method to measure carbon dioxide evolved from carbon substrate amendments so as to determine the physiological profiles of soil microbial communities by using whole soil. Appl. Environ. Microbiol. 69, 3593-3599.

Chen, J., Luo, Y.Q., Li, J.W., Zhou, X.H., Cao, J.J., Wang, R.W., Wang, Y.Q., Shelton, S., Jin, Z., Walker, L.M., Feng, Z.Z., Niu, S.L., Feng, W.T., Jian, S.Y., Zhou, L.Y., 2017. Costimulation of soil glycosidase activity and soil respiration by nitrogen addition. Glob. Chang. Biol. 23, 1328-1337.

Chen, R., Senbayram, M., Blagodatsky, S., Myachina, O., Dittert, K., Lin, X, Blagodatskaya, E., Kuzyakov, Y., 2014. Soil C and N availability determine the priming effect: microbial $\mathrm{N}$ mining and stoichiometric decomposition theories. Glob. Chang. Biol. 20, 2356-2367.

Cotrufo, M.F., Wallenstein, M.D., Boot, C.M., Denef, K., Paul, E., 2013. The Microbial Efficiency-Matrix Stabilization (MEMS) framework integrates plant litter decomposition with soil organic matter stabilization: do labile plant inputs form stable soil organic matter? Glob. Chang. Biol. 19, 988-995.

Creamer, C.A., Jones, D.L., Baldock, J.A., Farrell, M., 2014. Stoichiometric controls upon low molecular weight carbon decomposition. Soil Biol. Biochem. 79, 50-56.

Creamer, C.A., Jones, D.L., Baldock, J.A., Rui, Y., Murphy, D.V., Hoyle, F.C., Farrell, M., 2016. Is the fate of glucose-derived carbon more strongly driven by nutrient availability, soil texture, or microbial biomass size? Soil Biol. Biochem. 103, 201-212.

Creamer, R.E., Stone, D., Berry, P., Kuiper, I., 2016. Measuring respiration profiles of soil microbial communities across Europe using MicroResp ${ }^{\mathrm{TM}}$ method. Appl. Soil Ecol. 97, $36-43$.

Degens, B.P., 1997. Macro-aggregation of soils by biological bonding and binding mechanisms and the factors affecting these: a review. Aust. J. Soil Res. 35, 431-460.

Eivazi, F., Tabatabai, M., 1988. Glucosidases and galactosidases in soils. Soil Biol. Biochem. 20, 601-606.

Fernandes, E.C., Motavalli, P.P., Castilla, C., Mukurumbira, L., 1997. Management control of soil organic matter dynamics in tropical land-use systems. Geoderma 79, 49-67.

Fierer, N., Allen, A.S., Schimel, J.P., Holden, P.A., 2003. Controls on microbial $\mathrm{CO}_{2}$ production: a comparison of surface and subsurface soil horizons. Glob. Chang. Biol. 9, 1322-1332.

Fitzgerald, J.W. 1976. Sulfate ester formation and hydrolysis: a potentially important yet often ignored aspect of the soil sulfur cycle of aerobic soils. Bacteriol. Rev. 40, 698-721.

Fontaine, S., Mariotti, A., Abbadie, L., 2003. The priming effect of organic matter: a question of microbial competition? Soil Biol. Biochem. 35, 837-843.

Hedges, J.I., Eglinton, G., Hatcher, P.G., Kirchman, D.L., Arnosti, C., Derenne, S., Evershed, R.P., Kögel-Knabner, I., de Leeuw, J.W., Littke, R., 2000. The molecularlyuncharacterized component of nonliving organic matter in natural environments. Org. Geochem. 31, 945-958.

Heitkötter, J., Heinze, S., Marschner, B., 2017a. Relevance of substrate quality and nutrients for microbial C-turnover in top-and subsoil of a Dystric Cambisol. Geoderma 302, 89-99.

Heitkötter, J., Heinze, S., Marschner, B., 2017b. Patterns of nitrogen and citric acid in duced changes in C-turnover and enzyme activities are different in topsoil and subsoils of a sandy Cambisol. Geoderma 292, 111-117.

Hessen, D.O., Ågren, G.I., Anderson, T.R., Elser, J.J., De Ruiter, P.C., 2004. Carbon sequestration in ecosystems: the role of stoichiometry. Ecology 85, 1179-1192.

Hill, P.W., Farrar, J.F., Jones, D.L., 2008. Decoupling of microbial glucose uptake and mineralization in soil. Soil Biol. Biochem. 40, 616-624.

Jia, J., Feng, X., He, J.S., He, H., Lin, L., Liu, Z., 2017. Comparing microbial carbon sequestration and priming in the subsoil versus topsoil of a Qinghai-Tibetan alpine grassland. Soil Biol. Biochem. 104, 141-151.

Jobbagy, E.G., Jackson, R.B., 2000. The vertical distribution of soil organic carbon and its relation to climate and vegetation. Ecol. Appl. 10, 423-436.

Kell, D.B., 2011. Breeding crop plants with deep roots: their role in sustainable carbon, nutrient and water sequestration. Ann. Bot. 108, 407-418.

Kertesz, M.A., 1999. Riding the sulfur cycle - metabolism of sulfonates and sulfate esters in Gram-negative bacteria. FEMS Microbiol. Rev. 24, 135-175.

Kirkby, C.A., Richardson, A.E., Wade, L.J., Batten, G.D., Blanchard, C., Kirkegaard, J.A., 2013. Carbon-nutrient stoichiometry to increase soil carbon sequestration. Soil Biol. Biochem. 60, 77-86.

Kirkby, C.A., Richardson, A.E., Wade, L.J., Passioura, J.B., Batten, G.D., Blanchard, C., Kirkegaard, J.A., 2014. Nutrient availability limits carbon sequestration in arable soils. Soil Biol. Biochem. 68, 402-409.

Krull, E.S., Baldock, J.A., Skjemstad, J.O., 2003. Importance of mechanisms and processes of the stabilisation of soil organic matter for modelling carbon turnover. Funct. Plant Biol. 30, 207-222.

Kuzyakov, Y., 2010. Priming effects: interactions between living and dead organic matter. Soil Biol. Biochem. 42, 1363-1371.

Liang, C., Schimel, J.P., Jastrow, J.D., 2017. The importance of anabolism in microbial control over soil carbon storage. Nat. Microbiol. 2, 17105.

Lorenz, K., Lal, R., 2005. The depth distribution of soil organic carbon in relation to land use and management and the potential of carbon sequestration in subsoil horizons. Adv. Agron. 88, 35-66.

Lynch, J.P., Wojciechowski, T., 2015. Opportunities and challenges in the subsoil: pathways to deeper rooted crops. J. Exp. Bot. 66, 2199-2210.

Meyer, N., Welp, G., Bornemann, L., Amelung, W., 2017. Microbial nitrogen mining affects spatio-temporal patterns of substrate-induced respiration during seven years of bare fallow. Soil Biol. Biochem. 104, 175-184.

Meyer, N., Welp, G., Rodionov, A., Borchard, N., Martius, C., Amelung, W., 2018. Nitrogen and phosphorus supply controls soil organic carbon mineralization in tropical topsoil and subsoil. Soil Biol. Biochem. 119, 152-161.

Michalzik, B., Tipping, E., Mulder, J., Lancho, J.G., Matzner, E., Bryant, C., Clarke, N., Lofts, S., Esteban, M.V., 2003. Modelling the production and transport of dissolved organic carbon in forest soils. Biogeochemistry 66, 241-264.

Mooshammer, M., Wanek, W., Zechmeister-Boltenstern, S., Richter, A., 2014 Stoichiometric imbalances between terrestrial decomposer communities and their resources: mechanisms and implications of microbial adaptations to their resources. Front. Microbiol. 5, 22

Nordgren, A., 1988. Apparatus for the continuous long-term monitoring of soil respiration rate in large numbers of samples. Soil Biol. Biochem. 20, 955-958.

Orgill, S.E., Condon, J.R., Kirkby, C.A., Orchard, B.A., Conyers, M.K., Greene, R.S.B., Murphy, B.W., 2017. Soil with high organic carbon concentration continues to sequester carbon with increasing carbon inputs. Geoderma 285, 151-163.

Petersen, S.O., Hoffmann, C.C., Schafer, C.M., Blicher-Mathiesen, G., Elsgaard, L., Kristensen, K., Larsen, S.E., Torp, S.B., Greve, M.H., 2012. Annual emissions of $\mathrm{CH}_{4}$ and $\mathrm{N}_{2} \mathrm{O}$, and ecosystem respiration, from eight organic soils in Western Denmark managed by agriculture. Biogeosciences 9, 403-422.

Richardson, A.E., Lynch, J.P., Ryan, P.R., Delhaize, E., Smith, F.A., Smith, S.E., Harvey, P.R., Ryan, M.H., Venenklaas, E.J., Lambers, H., Oberson, A., Culvenor, R.A., Simpson, R.J., 2011. Plant and microbial strategies to improve the phosphorus efficiency of agriculture. Plant Soil 349, 121-156.

Rumpel, C., 2014. Opportunities and threats of deep soil organic matter storage. Carbon Manage. 5, 115-117.

Rumpel, C., Kögel-Knabner, I., 2011. Deep soil organic matter - a key but poorly understood component of terrestrial C cycle. Plant Soil 338, 143-158.

Salomé, C., Nunan, N., Pouteau, V., Lerch, T.Z., Chenu, C., 2010. Carbon dynamics in topsoil and in subsoil may be controlled by different regulatory mechanisms. Glob. Chang. Biol. 16, 416-426.

Schmidt, M.W.I., Torn, M.S., Abiven, S., Dittmar, T., Guggenberger, G., Janssens, I.A., Kleber, M., Kögel-Knabner, I., Lehmann, J., Manning, D.A.C., Nannipieri, P., Rasse, D.P., Weiner, S., Trumbore, S.E., 2011. Persistence of soil organic matter as an ecosystem property. Nature 478, 49-56.

Sinsabaugh, R.L., Manzoni, S., Moorhead, D.L., Richter, A., 2013. Carbon use efficiency of microbial communities: stoichiometry, methodology and modelling. Ecol. Lett. 16, 930-939.

Tian, Q., Yang, X., Wang, X., Liao, C., Li, Q., Wang, M., Wu, Y., Liu, F., 2016. Microbial community mediated response of organic carbon mineralization to labile carbon and nitrogen addition in topsoil and subsoil. Biogeochemistry 128, 125-139.

Van Veen, J.A., Ladd, J.N., Amato, M., 1985. Turnover of carbon and nitrogen through the microbial biomass in a sandy loam and a clay soil incubated with $\left[{ }^{14} \mathrm{C}(\mathrm{U})\right]$ glucose and $\left[{ }^{15} \mathrm{~N}\right]\left(\mathrm{NH}_{4}\right)_{2} \mathrm{SO}_{4}$ under different moisture regimes. Soil Biol. Biochem. 17, $747-756$.

von den Berg, R.A., Hoefsloot, H.C.J., Westerhuis, J.A., Smilde, A.K., van der Werf, M.J., 2006. Centering, scaling, and transformations: improving the biological information content of metabolomics data. BMC Genomics 7, 142.

von Lutzow, M., Kögel-Knabner, I., Ekschmitt, K., Matzner, E., Guggenberger, G., Marschner, B., Flessa, H., 2006. Stabilization of organic matter in temperate soils: mechanisms and their relevance under different soil conditions - a review. Eur. J. Soil Sci. 57, 426-445.

Wilhelm, W., Johnson, J.M., Hatfield, J., Voorhees, W., Linden, D., 2004. Crop and soil productivity response to corn residue removal. Agron. J. 96, 17.

Xu, X.F., Thornton, P.E., Post, W.M., 2013. A global analysis of soil microbial biomass carbon, nitrogen and phosphorus in terrestrial ecosystems. Glob. Ecol. Biogeogr. 22, 737-749.

Xu, X.F., Hui, D.F., King, A.W., Song, X., Thornton, P.E., Zhang, L.H., 2015. Convergence of microbial assimilations of soil carbon, nitrogen, phosphorus, and sulfur in terrestrial ecosystems. Sci. Rep. 5, 17445.

Zak, J.C., Willig, M.R., Moorhead, D.L., Wildman, H.G., 1994. Functional diversity of microbial communities: a quantitative approach. Soil Biol. Biochem. 26, 1101-1108.

Zar, J.H., 2010. Biostatistical Analysis, fifth edition. Prentice Hall, Inc., Upper Saddle River, NJ. 